NATIONAL LABORATORY

\title{
Assessment of Initial Test Conditions for Experiments to Assess Irradiation Assisted Stress Corrosion Cracking Mechanisms
}

\section{December 2010}

Prepared by

J.T. Busby and M.N. Gussev

Oak Ridge National Laboratory

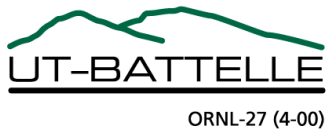



This report was prepared as an account of work sponsored by an agency of the United States Government. Neither the United States Government nor any agency thereof, nor any of their employees, makes any warranty, express or implied, or assumes any legal liability or responsibility for the accuracy, completeness, or usefulness of any information, apparatus, product, or process disclosed, or represents that its use would not infringe privately owned rights. Reference herein to any specific commercial product, process, or service by trade name, trademark, manufacturer, or otherwise, does not necessarily constitute or imply its endorsement, recommendation, or favoring by the United States Government or any agency thereof. The views and opinions of authors expressed herein do not necessarily state or reflect those of the United States Government or any agency thereof. 
ORNL/TM-2010/346

Light Water Reactor Sustainability

\title{
Assessment of Initial Test Conditions for Experiments to Assess Irradiation Assisted Stress Corrosion Cracking Mechanisms
}

\author{
J.T. Busby and M.N. Gussev \\ Materials Science and Technology Division \\ Oak Ridge National Laboratory
}

Date Published: December 2010

Prepared under the direction of the

U.S. Department of Energy

Office of Nuclear Energy

Light Water Reactor Sustainability

Materials Aging and Degradation Pathway

Prepared by

OAK RIDGE NATIONAL LABORATORY

Oak Ridge, Tennessee 37831-6283

managed by

UT-BATTELLE, LLC

for the

U.S. DEPARTMENT OF ENERGY

under contract DE-AC05-00OR22725 
This page intentionally left blank 



\section{CONTENTS}

Page

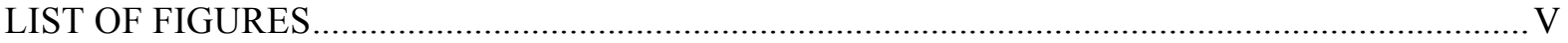

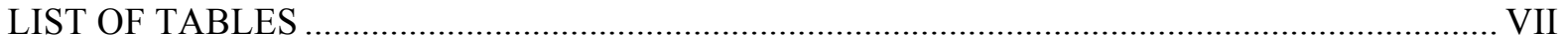

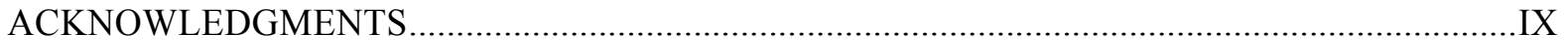

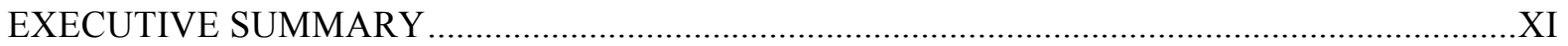

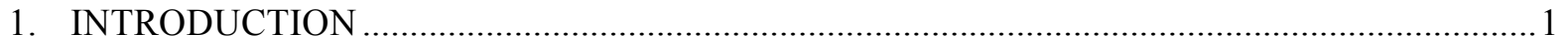

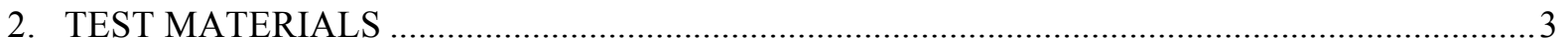

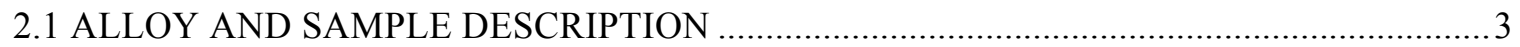

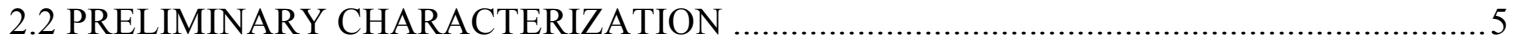

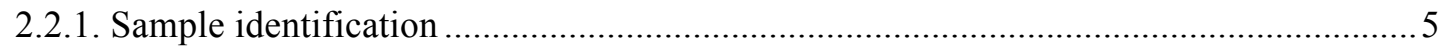

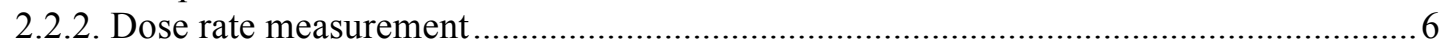

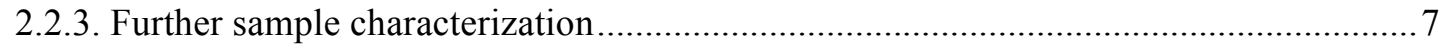

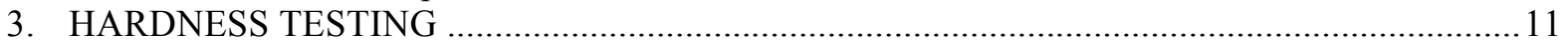

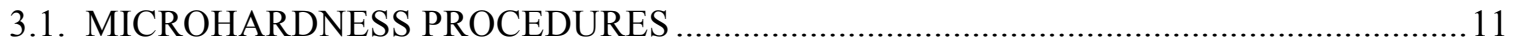

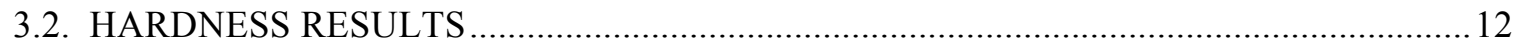

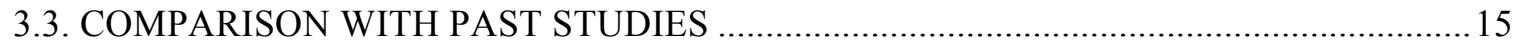

4. ANALYSIS OF DEFORMATION AROUND HARDNESS INDENTATIONS ........................ 17

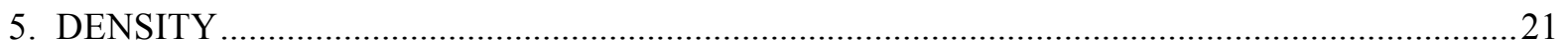

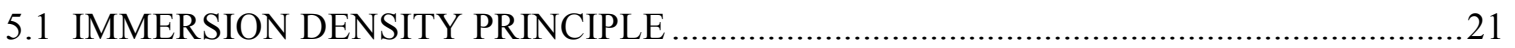

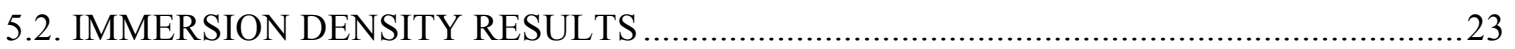

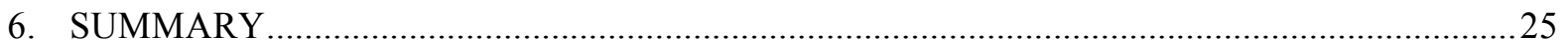

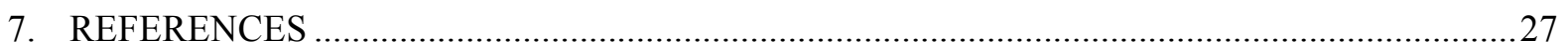


This page intentionally left blank 


\section{LIST OF FIGURES}

Figure

Page

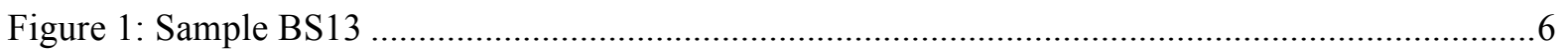

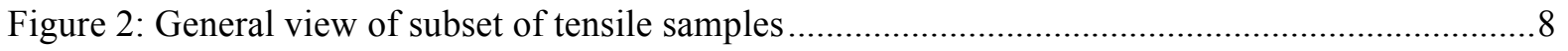

Figure 3: Sample with small fixture hole (at the left) comparing to the normal (expected) hole

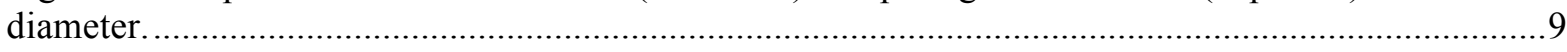

Figure 4: Deep coarse numbering: the coarse number of specimen (at the left) and unexpected undocumented characters (at the right).

Figure 5: Sample B123 surface (one of samples' heads). A clear surface with some insignificant amount of carbides and other inclusions is observed. Very light scratches are also visible. Sample handling caused the minor scratches on the heads.

Figure 6: Microhardness value as function of load. For most soft and hard specimens the 3\% error

bars are shown steel in light water reactors.

Figure 8: Examples of typical indenter indent geometry: a) HS-13 sample, 500 g load. b) ES-21, 500

g. c) BS-13, $100 \mathrm{~g}$.

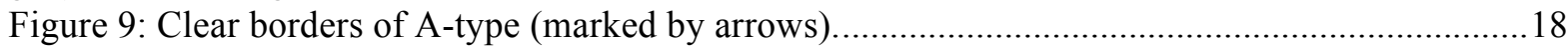

Figure 10: Borders of B-type (marked by arrows). One can see formless "hills" of material.............18 Figure 11: Borders of C-type (marked by arrows). It is possible to see deformation lines as "parquet-

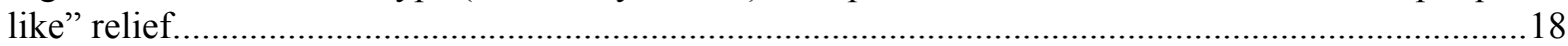

Figure 12: Examples of compels boundary Most of boundaries' perimeter is C-type boundary. .......19 Figure 13: Examples of compels boundary with C (solid line) and B (dot line) parts. PS-15, 500g....19 Figure 14: Temperature dependence of FC-43 density. 
This page intentionally left blank 


\section{LIST OF TABLES}

\section{Table}

Page

Table 1: Chemical composition of CIR alloys (compositions in at \%) 3

Table 2: Inventory of compact tension specimens for this effort 4

Table 3: Inventory of tensile specimens for this effort 5

Table 4: Summary of dose rate measurements on specimens. $\quad 7$

Table 5:Microhardness values for initial batch of tensile specimens. 12

Table 6:Microhardness values for initial batch of tensile specimens (500 g load). 14

Table 7: Fraction of different stricture types $(A, B, C)$ for different loads. $\quad 20$

Table 8: Density values for first set of BOR-60 samples 24 
This page intentionally left blank 


\section{ACKNOWLEDGMENTS}

This research was sponsored by the U.S. Department of Energy, Office of Nuclear Energy, for the Light Water Reactor Sustainability Research and Development effort. The authors are also appreciative to Drs. T. Rosseel and L. Tan for their input and suggestions. 
This page intentionally left blank 


\section{EXECUTIVE SUMMARY}

Irradiation-assisted stress corrosion cracking is a key materials degradation issue in today's nuclear power reactor fleet and affects critical structural components within the reactor core. The effects of increased exposure to irradiation, stress, and/or coolant can substantially increase susceptibility to stress-corrosion cracking of austenitic steels in high-temperature water environments. Despite 30 years of experience, the underlying mechanisms of Irradiation Assistaed Stress Corrosion Cracking (IASCC) are unknown. Extended service conditions will increase the exposure to irradiation, stress, and corrosive environments for all core internal components. The objective of this effort within the Light Water Reactor Sustainability (LWRS) program is to evaluate the response and mechanisms of IASCC in austenitic stainless steels with single variable experiments.

A series of high-value irradiated specimens has been acquired from the past international research programs, providing a valuable opportunity to examine the mechanisms of IASCC. This batch of irradiated specimens has been received and inventoried. In addition, visual examination and sample cleaning has been completed.

Microhardness testing has been performed on these specimens. All samples show evidence of hardening, as expected, although the degree of hardening has saturated and no trend with dose is observed. Further, the change in hardening can be converted to changes in mechanical properties. The calculated yield stress is consistent with previous data from light water reactor conditions.

In addition, some evidence of changes in deformation mode was identified via examination of the microhardness indents. This analysis may provide further insights into the deformation mode under larger scale tests.

Finally, swelling analysis was performed using immersion density methods. Most alloys showed some evidence of swelling, consistent with the expected trends for this class of alloy. The Hf-doped alloy showed densification rather than swelling. This observation may be related to the formation of second-phases under irradiation, although further examination is required. 
This page intentionally left blank 


\section{INTRODUCTION}

Nuclear power currently provides a significant fraction of the United States' non-carbon emitting power generation. In future years, nuclear power must continue to generate a significant portion of the nation's electricity to meet the growing electricity demand, clean energy goals, and ensure energy independence. New reactors will be an essential part of the expansion of nuclear power. However, given limits on new builds imposed by economics and industrial capacity, the extended service of the existing fleet will also be required.

Ensuring public safety and environmental protection is a prerequisite to all nuclear power plant operating and licensing decisions at all stages of reactor life. This includes the original license period of 40 years, the first license extension to 60 years, and certainly for any consideration of life beyond 60 years. For extended operating periods, it must be shown that adequate aging management programs are present or planned and that appropriate safety margins exist throughout the subsequent license renewal periods. Materials degradation can impact reactor reliability, availability, and potentially, safe operation. Components within a reactor must tolerate the harsh environment of high temperature water, stress, vibration, and/or an intense neutron field. Degradation of materials in this environment can lead to reduced performance, and in some cases, sudden failure. Clearly, understanding materials degradation and accounting for the effects of a reactor environment in operating and regulatory limits is essential.

The Light Water Reactor Sustainability (LWRS) Program is designed to support the long-term operation (LTO) of existing domestic nuclear power generation with targeted collaborative research programs into areas beyond current short-term optimization opportunities [1]. Within the LWRS program, four pathways have been initiated to perform research essential to informing relicensing decisions [1]. The Materials Aging and Degradation Pathway is designed to help develop the scientific basis for understanding and predicting long-term environmental degradation behavior of materials in nuclear power plants and to provide data and methods to assess performance of systems, structures, and components essential to safe and sustained operation.

The effects of irradiation can substantially increase susceptibility to stress-corrosion cracking of austenitic steels in high-temperature water environments. This form of degradation, termed irradiation-assisted stress-corrosion cracking (IASCC), has been observed in both boiling water reactors (BWRs) and pressurized water reactors (PWRs), although higher irradiation doses are required for the onset of IASCC in PWR's. Both 304 and 316 stainless steel are susceptible to this form of degradation. For regulators and industry, IASCC is a key materials degradation issue in today's nuclear power reactor fleet and affects critical structural components within the reactor core. With additional exposure to the combined effects of coolant, stress, and irradiation under extended service, this form of degradation is expected to grow more severe and additional materials may become susceptible. Despite 30 years of experience, the underlying mechanisms of IASCC are unknown.

The objective of this work is to evaluate the response and mechanisms of IASCC in austenitic stainless steels with single variable experiments. Crack growth rate tests and complementary microstructure analysis will provide a more complete understanding of IASCC by building on past Electrical Power Research Institute (EPRI)-led work for the Cooperative IASCC Research Group. Experimental research will include crack-growth testing on high-fluence specimens of single-variable alloys in simulated LWR environments, tensile testing, hardness testing, microstructural and microchemical analysis, and detailed efforts to characterize localized deformation. This is a collaborative research effort lead by the University of Michigan with Oak Ridge National Laboratory and Pacific Northwest National Laboratory providing support. A detailed description of the larger 
effort, sample matrix, and single-variable experiment plan is given in Ref. [2].

In this report, the characterization of an initial set of test specimens is provided. This analysis includes hardness testing, deformation evaluation and an estimation of swelling. These complementary bits of analysis provide key information that, when combined with the mechanical testing performed in simulated LWR environments, will provide better understanding of the driving forces for IASCC and help identify mitigation strategies. 


\section{TEST MATERIALS}

As noted in Ref. [2], this effort builds heavily on past research and programs conducted by the Cooperative IASCC Research (CIR) programs. The objective of the CIR program was to help develop predictive models and mitigations strategies for IASCC. Progress in this program included a detailed-white paper review on IASCC subjects and a systematic and detailed characterization of irradiation-induced microstructure and cracking response in stainless steels (from both neutron and proton-irradiations).

\subsection{ALLOY AND SAMPLE DESCRIPTION}

In addition, the CIR program also conducted an irradiation campaign in the BOR-60 reactor including a series of 20 single-variable alloys with different compositions and thermo-mechanical states. The alloys are described in Table 1. The CIR program concluded crack-growth testing on a number of these irradiated conditions. That effort provides a solid foundation for this program.

Table 1: Chemical composition of CIR alloys (compositions in at \%)

\begin{tabular}{|c|c|c|c|c|c|c|c|c|c|c|c|c|c|c|c|c|}
\hline Alloy & Note & C & Mn & Si & $\mathbf{P}$ & $S$ & $\mathrm{Cr}$ & $\mathrm{Ni}$ & Mo & $N$ & $\mathrm{Nb}$ & $\mathrm{Ti}$ & 0 & Co & $\mathrm{Cu}$ & $\mathrm{Hf}$ \\
\hline$A$ & Commercial & 0.023 & 1.82 & 0.56 & 0.023 & 0.015 & 19.95 & 10.8 & 0.53 & 0.072 & $<0.001$ & 0.02 & 0.011 & 0.22 & 0.29 & \\
\hline B & Commercial & 0.056 & 1.13 & 0.73 & 0.022 & 0.022 & 16.84 & 10.54 & 2.25 & 0.021 & 0.008 & 0.01 & 0.009 & 0.12 & 0.25 & \\
\hline C & Commercial & 0.07 & 1.4 & 0.56 & 0.013 & 0.007 & 16.77 & 12.78 & 2.18 & 0.008 & $<0.01$ & 0.38 & 0.004 & 0.1 & 0.06 & \\
\hline SW & $\begin{array}{c}\text { Swedish } \\
\text { commercial }\end{array}$ & 0.022 & 1.07 & 0.24 & 0.015 & $<0.002$ & 18.42 & 10.45 & - & 0.025 & - & - & - & - & - & \\
\hline$E$ & HP & 0.021 & 0.94 & 0.04 & $<0.01$ & 0.003 & 18.76 & 12.37 & 0.04 & 0.0003 & 0.005 & 0.01 & 0.004 & 0.01 & $<0.01$ & \\
\hline $\mathrm{F}$ & HP & 0.008 & 0.98 & 0.03 & $<0.01$ & 0.003 & 18.17 & 12.06 & 0.02 & 0.0005 & 0.002 & 0.01 & 0.013 & 0.01 & $<0.01$ & \\
\hline G & HP & 0.02 & 0.97 & 0.03 & $<0.01$ & 0.002 & 18.26 & 12.15 & 2.36 & 0.0004 & 0.003 & 0.01 & 0.005 & 0.01 & 0.01 & \\
\hline $\mathrm{H}$ & $\mathrm{HP}$ & 0.02 & 1.01 & 1.05 & $<0.01$ & 0.002 & 18.17 & 12.45 & 0.02 & 0.0005 & $<0.001$ & 0.01 & 0.007 & 0.01 & $<0.01$ & \\
\hline 1 & HP & 0.007 & 1.01 & 0.03 & 0.016 & 0.003 & 18.21 & 12.11 & 0.02 & 0.0004 & $<0.001$ & 0.01 & 0.012 & 0.01 & $<0.01$ & \\
\hline K & HP & 0.02 & 1 & 0.03 & $<0.01$ & 0.002 & 18.21 & 25.08 & 0.02 & 0.0005 & $<0.001$ & 0.01 & 0.003 & 0.01 & $<0.01$ & \\
\hline L & HP & 0.02 & 1.02 & 0.03 & $<0.01$ & 0.002 & 25.22 & 25.07 & 0.02 & 0.0005 & $<0.001$ & 0.01 & 0.009 & 0.01 & 0.01 & \\
\hline$M$ & HP & 0.02 & 1 & 0.03 & $<0.01$ & 0.003 & 18.03 & 11.22 & 0.02 & 0.0005 & $<0.001$ & 0.3 & 0.011 & 0.73 & $<0.01$ & \\
\hline $\mathrm{N}$ & HP & 0.02 & 1 & 0.03 & $<0.01$ & 0.003 & 18.24 & 12.12 & 0.02 & 0.0004 & 0.595 & 0.01 & 0.004 & 0.01 & $<0.01$ & \\
\hline$P$ & HP & 0.028 & 1.01 & 0.1 & 0.01 & 0.007 & 17.03 & 13.6 & 2.18 & & & & & & & 1.17 \\
\hline
\end{tabular}


In addition to the wealth of previous data, the CIR program also had a series of key untested specimens. The LWRS program has acquired these samples and preliminary characterization has been completed as noted in a section below. The crack-growth specimen conditions and tensile specimen conditions are shown in Tables 2 and 3, respectively. More details on each of the specimen conditions are given in [2].

Table 2: Inventory of compact tension specimens for this effort

\begin{tabular}{|c|c|c|c|c|c|c|}
\hline Specimen No. & CG-BS01 & CG-G S01 & CGIP01 & CG-M S01 & CG-NS01 & CG-PS02 \\
\hline Heat Serial & BS & GS & IP & MS & NS & PS \\
\hline Material & 316 & 304 & $\begin{array}{c}304 \\
\text { (SA 304L) }\end{array}$ & 304 & 304 & $316 \mathrm{~L}$ \\
\hline Material Type & SA, Baffle Bolt & HP & HP & HP & HP & HP \\
\hline Solute Additions & None & Mo & - C, P & Ti & Nb & Hf \\
\hline Dose, dpa & 5.5 & 11.8 & 4.4 & 10.7 & 10.7 & 9.6 \\
\hline Reactor & Boris 6 & Boris 6 & Boris 7 & Boris 7 & Boris 7 & Boris 7 \\
\hline $\begin{array}{c}\text { Date of Out the } \\
\text { Reactor }\end{array}$ & Oct. 2001 & Oct. 2002 & June, 2004 & June, 2004 & June, 2004 & Oct. 2003 \\
\hline $\begin{array}{c}\text { Specimen Type } \\
\text { RCT }\end{array}$ & RCT & RCT & RCT & RCT & RCT \\
\hline Specimen Thickness & $8 \mathrm{~mm}$ & $6 \mathrm{~mm}$ & $8 \mathrm{~mm}$ & $8 \mathrm{~mm}$ & $8 \mathrm{~mm}$ & $8 \mathrm{~mm}$ \\
\hline
\end{tabular}


Table 3: Inventory of tensile specimens for this effort

\begin{tabular}{|c|c|c|c|c|c|c|c|c|}
\hline No. & Specimen & Material & $\begin{array}{c}\text { Material } \\
\text { Type }\end{array}$ & Heat Serial & $\begin{array}{c}\text { Solute } \\
\text { Additions }\end{array}$ & Reactor & $\begin{array}{c}\text { Date out of } \\
\text { reactor }\end{array}$ & Dose, dpa \\
\hline 1 & AS13 & $304 \mathrm{~L}$ & SA, Shroud & $\mathrm{AS}$ & None & Boris 6 & Ot., 2001 & 5.5 \\
\hline 2 & AS14 & $304 \mathrm{~L}$ & SA, Shroud & AS & None & Boris 6 & Oct., 2001 & 5.5 \\
\hline 3 & AS 17 & $304 \mathrm{~L}$ & SA. Shroud & $\mathrm{AS}$ & None & Boris 6 & Qt.., 2002 & 10.2 \\
\hline 4 & AS18 & $304 \mathrm{~L}$ & SA, Shroud & AS & None & Boris 6 & Ott., 20002 & 10.2 \\
\hline 5 & AS19 & $304 \mathrm{~L}$ & SA, Shroud & AS & None & Boris 6 & Oct., 2002 & 10.2 \\
\hline 6 & BS13 & 316 & SA, Bolt & $\mathrm{BS}$ & None & Boris 6 & Oct., 2001 & 5.5 \\
\hline 7 & $\mathrm{BS} 16$ & 316 & SA, Bolt & $\mathrm{BS}$ & None & Boris 6 & Oct., 2002 & 10.2 \\
\hline 8 & BR15 & 316 & CW, Bolt & $\mathrm{BR}$ & None & Boris 6 & Mar., 2003 & 4.8 \\
\hline 9 & $\mathrm{~B} 124(2)$ & 316 & CW, Bolt & $B$ & None & Boris 6 & Mar., 2003 & 25 \\
\hline 10 & $\mathrm{~B} 125(3)$ & 316 & CW, Bolt & $\mathrm{B}$ & None & Boris 6 & Mar., 2003 & 25 \\
\hline 11 & $B 126$ & 316 & CW, Bolt & $\mathrm{B}$ & None & Boris 6 & Mar., 2003 & 25 \\
\hline 12 & CR13 & 316 & CW, Ti St. & CR & $\mathrm{Ti}$ & Boris 6 & Mar., 2003 & 4.8 \\
\hline 13 & CR14 & 316 & CW, Ti St. & CR & $\mathrm{Ti}$ & Boris 6 & Mar., 2003 & 4.8 \\
\hline 14 & (CRI 7) & 316 & CW, Ti St. & CR & $\mathrm{Ti}$ & Boris 6 & Mar., 2003 & 25 \\
\hline 15 & (CR18) & 316 & CW, Ti St. & CR & $\mathrm{Ti}$ & Boris 6 & Mar., 2003 & 25 \\
\hline 16 & CR19 & 316 & CW, Ti St. & CR & $\mathrm{Ti}$ & Boris 6 & Mar., 2003 & 25 \\
\hline 17 & ES13 & 304 & $\mathrm{HP}$ & ES & None & Boris 6 & Ott., 2002 & 11.8 \\
\hline 18 & ES14 & 304 & $\mathrm{HP}$ & ES & None & Boris 6 & Oct., 2002 & 11.8 \\
\hline 19 & ES16 & 304 & $\mathrm{HP}$ & ES & None & Boris 6 & Oet., 2002 & 10.2 \\
\hline 20 & GS13 & 304 & $\mathrm{HP}$ & GS & Mo & Boris 6 & Oct., 2002 & 11.8 \\
\hline 21 & GS14 & 304 & $\mathrm{HP}$ & GS & Mo & Boris 6 & Ot., 2002 & 11.8 \\
\hline 22 & A.S22 & $304 \mathrm{~L}$ & SA, Shroud & $\mathrm{AS}$ & None & Boris 7 & June, 2004 & 47.5 \\
\hline 23 & AS23 & $304 \mathrm{~L}$ & SA, Shroud & $\mathrm{AS}$ & None & Boris 7 & June, 2004 & 47.5 \\
\hline 24 & BS18 & 316 & SA, Bolt & $\mathrm{BS}$ & None & Boris 7 & June, 2004 & 47.5 \\
\hline 25 & ES21 & 304 & $\mathrm{HP}$ & ES & None & Boris 7 & June, 2004 & 10.7 \\
\hline 26 & $\mathrm{LS} 13$ & 304 & $\mathrm{HP}$ & $\mathrm{LS}$ & $\mathrm{Cr}, \mathrm{Ni}$ & Boris 7 & Oct., 2003 & 9.1 \\
\hline 27 & $\mathrm{FS} 13$ & 304 & $\mathrm{HP}$ & $\mathrm{FS}$ & $-\mathrm{C}$ & Boris 7 & Qte., 2003 & 9.1 \\
\hline 28 & HS 13 & 304 & $\mathrm{HP}$ & $\mathrm{HS}$ & $\mathrm{Si}$ & Boris 7 & Ott., 2003 & 7.8 \\
\hline 29 & $\mathrm{KS} 13$ & 304 & $\mathrm{HP}$ & $\mathrm{KS}$ & $\mathrm{Ni}$ & Boris 7 & Oet., 2003 & 9.6 \\
\hline 30 & PS13 & 304 & $\mathrm{HP}$ & PS & Hf & Boris 7 & Ot., 2003 & 9.6 \\
\hline 31 & PS14 & 304 & $\mathrm{HP}$ & $\mathrm{PS}$ & $\mathrm{Hf}$ & Boris 7 & Qct., 2003 & 9.6 \\
\hline 32 & PS15 & 304 & $\mathrm{HP}$ & $\mathrm{PS}$ & $\mathrm{Hf}$ & Boris 7 & Qt., 2003 & 9.6 \\
\hline 33 & $5 W 36$ & $304 \mathrm{~L}$ & SA, Swedish & $\mathrm{SW}$ & None & Boris 7 & June, 2004 & 4.4 \\
\hline 34 & $5 W 37$ & $304 \mathrm{~L}$ & SA. Swedish & $\mathrm{SW}$ & None & Boris 7 & June, 2004 & 4.4 \\
\hline
\end{tabular}

* CR 17 and CR 18 are missing; $\mathrm{B} 122$ and $\mathrm{B} 123$ are available.

\subsection{PRELIMINARY CHARACTERIZATION}

In late July 2010, a shipment of radioactive specimens was received at ORNL from Studsvik. A total of 33 specimens were part of that shipment, including 27 tensile specimens and 6 compact tensile specimens. Initial characterization and testing has included several key steps. First, samples were inventoried and inspected. Dose rates were measured. A subset of samples has been transferred from the Irradiated Materials Examination and Testing (IMET) hot cell to a low radioactive facility. Further specimen characterization has been performed. These initial steps are described in the sections below.

\subsubsection{Sample identification}

As noted above, a total of 33 specimens were received at the ORNL IMET hot cell facility. All expected specimens were accounted for, including 27 tensile specimens and 6 compact tension 
specimens. All specimens were positively identified by a series of engraved identification numbers. An example is shown in Figure 1.

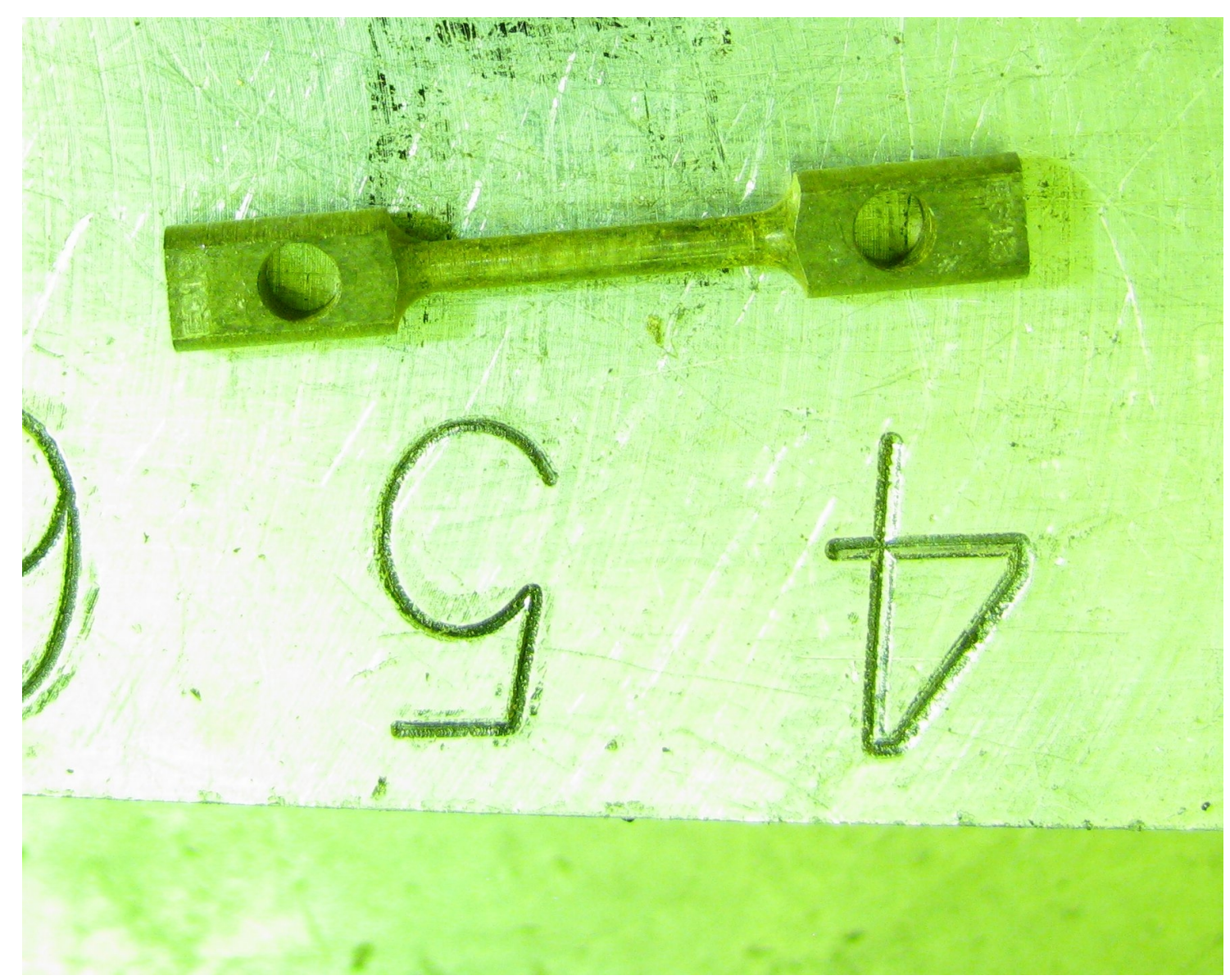

Figure 1: Sample BS13

\subsubsection{Dose rate measurement}

Dose rate measurements have been taken for all 33 specimens. The results are shown in Table 4 for each specimen. The dose rates are lower than expected for stainless steel specimens to high fluence, but this enables other testing options. 
Table 4: Summary of dose rate measurements on specimens.

\begin{tabular}{|c|c|c|}
\hline Sample ID & Sample Type & Dose rate $(\mathrm{mR} / \mathrm{hr}$ at $30 \mathrm{~cm})$ \\
\hline BS01 & $1 \mathrm{CT}$ & 80 \\
\hline GS01 & $1 \mathrm{CT}$ & 30 \\
\hline IP01 & $1 \mathrm{CT}$ & 60 \\
\hline MS01 & $1 \mathrm{CT}$ & 130 \\
\hline NS01 & $1 \mathrm{CT}$ & 140 \\
\hline PS02 & $1 \mathrm{CT}$ & 100 \\
\hline AS13 & TENSILE & 19 \\
\hline AS14 & TENSILE & 18 \\
\hline AS17 & TENSILE & 38 \\
\hline AS18 & TENSILE & 38 \\
\hline AS19 & TENSILE & 34 \\
\hline AS22 & TENSILE & 150 \\
\hline AS23 & TENSILE & 150 \\
\hline B122 & TENSILE & 14 \\
\hline B123 & TENSILE & 14 \\
\hline BR15 & TENSILE & 12 \\
\hline BS13 & TENSILE & 11 \\
\hline BS16 & TENSILE & 20 \\
\hline BS18 & TENSILE & 9 \\
\hline CR13 & TENSILE & 13 \\
\hline CR14 & TENSILE & 10 \\
\hline ES13 & TENSILE & 35 \\
\hline ES14 & TENSILE & 9 \\
\hline ES16 & TENSILE & 7 \\
\hline ES21 & TENSILE & 15 \\
\hline FS13 & TENSILE & 107 \\
\hline GS13 & TENSILE & 9 \\
\hline GS14 & TENSILE & 9 \\
\hline HS13 & TENSILE & 300 \\
\hline KS13 & TENSILE & 16 \\
\hline PS13 & TENSILE & 14 \\
\hline PS14 & TENSILE & 12 \\
\hline PS15 & TENSILE & 13 \\
\hline
\end{tabular}

\subsubsection{Further sample characterization}

The lower dose rates for the tensile specimens permits additional options in sample characterization and analysis since non-hot cell facilities can be utilized. In particular, the Low Activation Materials Design and Analysis (LAMDA) laboratories at ORNL are ideal for such work. In late August, the first 8 tensile specimens were transferred to the LAMDA facility from IMET. An additional characterization has been performed to assess sample polishing and cleaning needs.

The first batch of specimens, including BS13, BS16, BS18, ES14, ES21, GS14, PS15, and B123 were examined in September. It was important to estimate samples conditions, find any damage and unexpected peculiarities, and define further steps. Samples are shown in Figure 2. 


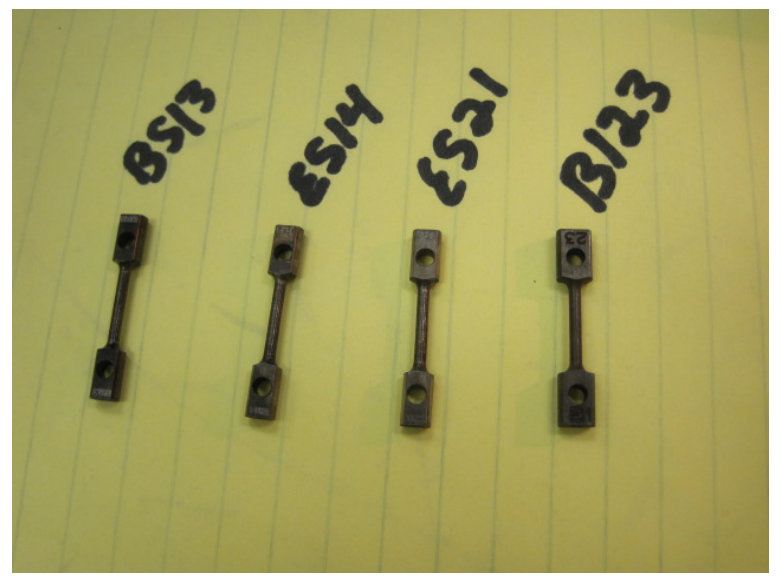

Figure 2: General view of subset of tensile samples

All samples were found to have an oxide layer with color varying from gray or metallic to dark blue and black. An electro-polishing will be required prior to density and electro-resistivity measurement.

Further, all samples have gauge sections with light traces (steps of $\sim 100-200 \mu \mathrm{m}$, and gouges $\sim 20-50$ $\mu \mathrm{m})$ from a cutting tool. Before mechanical testing, preliminary mechanical polishing, and last electro-chemical polishing will be required. Also the flat surfaces of samples' heads (for all samples) need to be polished prior to microhardness measurements. No serious damage (bend, traces of blows, deep scratches) was found.

Three kinds of unexpected defects were found.

- Samples PS15 and BS18 have small holes for sample fixture (see Figure 3). This can lead to additional problems during mechanical testing, but there is an advantage: more space is available for indentation. If possible, any additional drilling of these samples should be avoided.

- End faces of many samples have holes of different depth (from 0.1 to 1-1.5 mm). After electro polishing it is required to check these holes for contamination by oxides etc.

- There are undocumented marks on heads of some samples (see Figure 4). It is a very coarse and deep numbering (indents of numbering tool), so most chances these heads cannot be used for ball indentation (but still available for annealing experiments etc...).

Another anomaly is the size of the loading hole and variation in that dimension as shown in Figure 3. In the case of serious deformation hardening and increasing loads these locations can be involved in severe deformation. Prior to testing this must be carefully evaluated using experiments with unirradiated samples with comparable strength levels. 

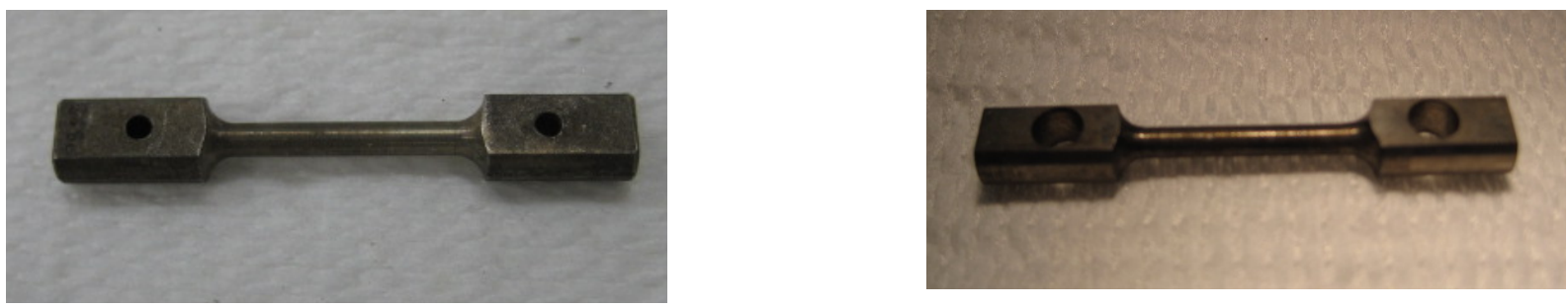

Figure 3: Sample with small fixture hole (at the left) comparing to the normal (expected) hole diameter.
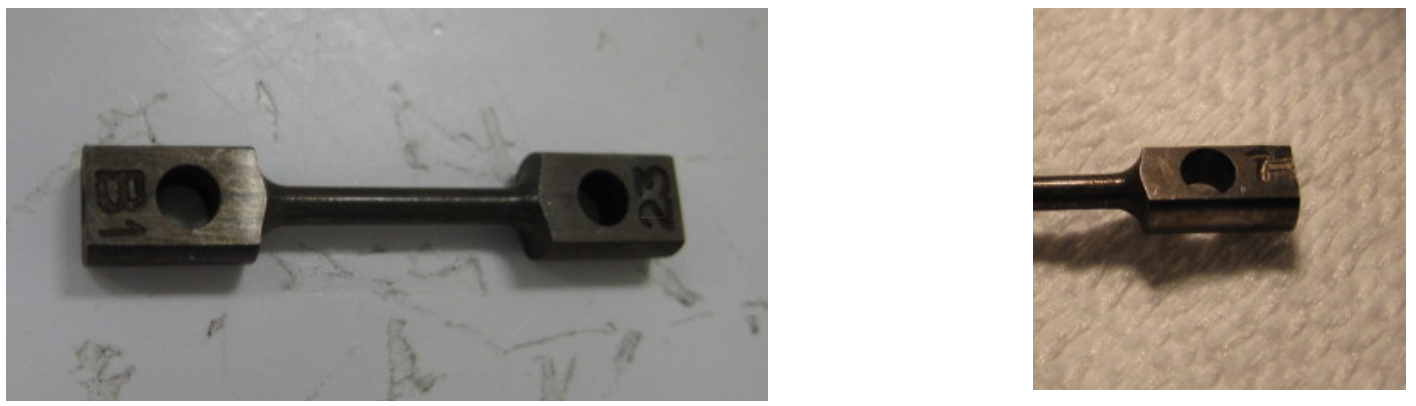

Figure 4: Deep coarse numbering: the coarse number of specimen (at the left) and unexpected undocumented characters (at the right). 



\section{HARDNESS TESTING}

The direct measurement of yield strength of irradiated materials is the most desirable way to monitor irradiation-induced hardening. However, the handling and testing of samples with high residual radioactivity is more difficult as the testing must be performed in hot cells. As such, the yield stress of a neutron-irradiated alloy can be difficult to determine when compared to unirradiated materials. Correlations have been developed which allow calculation of expected yield strengths from measured microstructural features such as dislocation loops and voids. However, the existing database of radiation-induced microstructure is also relatively sparse and the correlations are not yet widely developed for all alloys of interest.

Microhardness testing provides an alternative means of assessing changes in mechanical properties. Vickers hardness testing can be done quickly and efficiently, without need for a large volume of sample material; an important consideration for highly radioactive neutron-irradiated materials. Microhardness testing is also quasi-non-destructive leaving much of the sample available for other tests.

In this effort, microhardness has been utilized to provide an initial estimate of hardening on the ends of the tensile bars. This data will help provide complementary data to the mechanical testing that will be performed in water. Initially, this testing has been performed on eight specimens that will comprise the first two tensile tests in water.

\subsection{MICROHARDNESS PROCEDURES}

Hardness was measured on irradiated tensile specimens of each alloy and on unirradiated materials where available. Hardness measurements were performed using a Wilson Instruments hardness indenter equipped with a Vickers indenter tip. All indents were made on the end regions of the specimen, well away from the gage length so that later tensile tests are not influenced.

Indentations were performed with a Vickers indenter tip using a $0.1,0.2$, and $0.5 \mathrm{~kg}$ load. The dwell time was set at 15 seconds for all indents. Nominally, at least five indents were taken on each specimen. Before measurement of irradiated samples, the calibration and accuracy of the microhardness device was checked with help of 2 etalon calibration samples with known microhardness values. The check of accuracy was conducted at the beginning and ending of each day of testing. In all cases the difference between etalon specimens' nominal microhardness and device actual readings did not exceed $2 \%$. An average deviation was about $1.5 \%$, within the expected range of deviation for the calibration samples.

All irradiated samples were electropolished prior to microhardness measurements. Surface quality was sufficient in all cases, as there were no rough scratches, dirt, or contaminations. In some cases very light scratches caused by handling were found (see Figure 5). Unscratched areas were selected for indentation as much as possible. In all cases the distance between indentations was more than 2.5(2.5 what?) of diagonal's size as recommended by the ASTM E384 standard. However, the ASTM E384 standard also recommends to use a load value high enough to achieve indentation size about $50 \%$ of the viewing area. In this case it was impossible because of the high strength of materials under investigation. Even if a $500 \mathrm{~g}$ load was used the indentation size did not exceed $\sim 30 \%$ of visible screen area. 


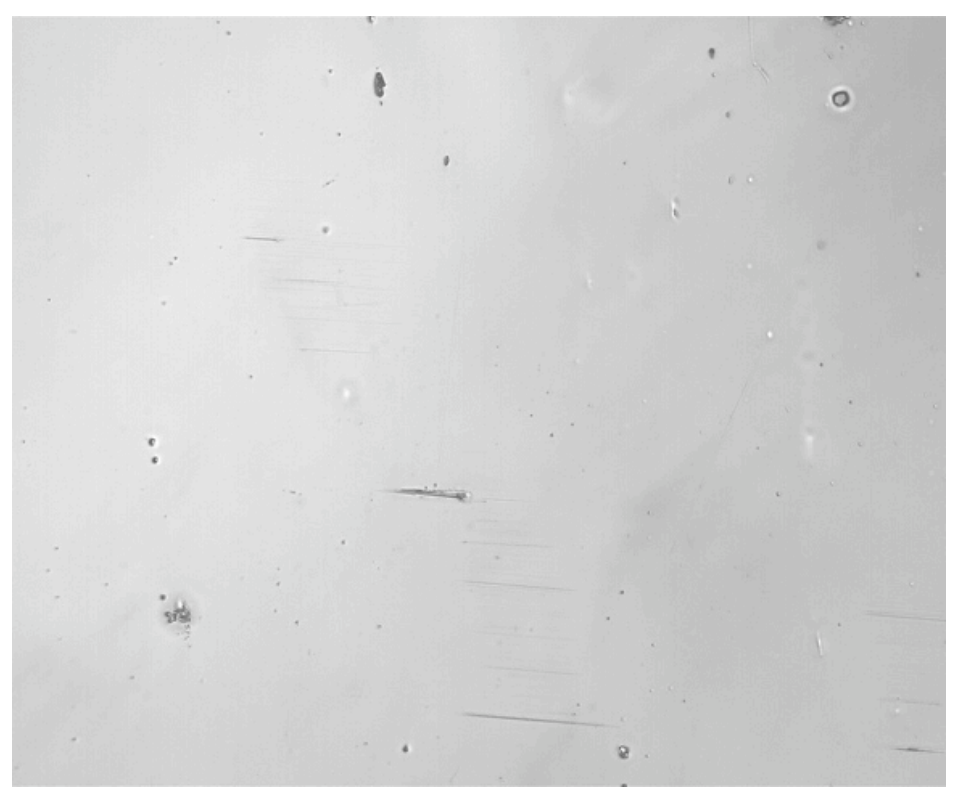

Figure 5: Sample B123 surface (one of samples' heads). A clear surface with some insignificant amount of carbides and other inclusions is observed. Very light scratches are also visible. Sample handling caused the minor scratches on the heads.

\subsection{HARDNESS RESULTS}

As noted above, three different loads were used during the measurements: 100, 200 and $500 \mathrm{~g}$. The different loads provide several key advantages. Firstly, the use of different loads gives ability to check the present of surface deformation. In addition, different loads allow for investigation of irradiated material deformation peculiarities around indentation, as will be discussed in a later section. The results of microhardness measurements are given in Table 5. In all cases the microhardness data is an average value of 5 or more independent measurements (except BS16 - 3 indentation for each load value).

Table 5:Microhardness values for initial batch of tensile specimens.

\begin{tabular}{|c|c|c|c|c|c|}
\hline Sample code & Material & Dose, dpa & load 100 g. & load 200g & load 500g \\
\hline ES21 & HP304 SS & 10.7 & 361 & 358 & 356 \\
\hline B123 & CW316 & 25 & 415 & 393 & 398 \\
\hline BS13 & SA316* & 5.5 & 467 & 467 & 453 \\
\hline BS16 & SA316* & 10.2 & 489 & 469 & 481 \\
\hline ES14 & HP304L & 11.8 & 364 & 364 & 348 \\
\hline GS14 & HP304+Mo & 11.8 & 371 & 352 & 350 \\
\hline HS13 & HP304+Si & 7.8 & 388 & 372 & 363 \\
\hline PS15 & HP304+Hf & 9.6 & 337 & 331 & 326 \\
\hline
\end{tabular}

* Possibly, these samples were not annealed, but were cold worked. 
Most data points are in interval $300-400 \mathrm{~kg} / \mathrm{cm}^{2}$, this dispersion in results is typical for highly irradiated stainless steels. However, there are 2 exceptions to this data range: BS13 and BS16 samples, microhardness values for these samples are significantly above $400 \mathrm{~kg} / \mathrm{cm}^{2}$.

When a value of $500 \mathrm{~kg} / \mathrm{cm}^{2}$ was received for sample BS16, the measurement was interrupted, irradiated sample was removed and the microhardness device was re-checked with etalon samples. There were not any errors during measurement of etalon samples (only usual $\sim 1-2 \%$ deviation), so it was found device is fully functional. After that the measurement of the BS16 sample was repeated with reduced program ( 3 indentations per load instead of 5). This is the data shown in the table above. The same procedure (irradiated sample removal, checking with control sample or both, remeasurement of irradiated sample) was executed for BS13 (microhardness above 450) and PS15 (microhardness significantly below 350 , the softest sample).

Upon further evaluation, it was determined that the BS sample condition was not in the solution annealed state. Rather, all the BS specimens in the CIR program were irradiated in the cold-worked condition (approximately 20\% cold-worked). When this different starting condition is considered, the higher hardness levels for samples BS13 and BS16 is sensible.

Figure 6 shows microhardness value as function of load. One should note there are no critical differences between microhardness values for smallest (100g) and highest $(500 \mathrm{~g})$ loads. Typically, the difference does not exceed $3-5 \%$ between the loads indicating the quality of surface is sufficient and that there is no cold work on the surface or any other anomaly.

It is also possible to see that with increasing load, the microhardness value decreases and goes to some "saturated" value. This phenomenon is well known for un-irradiated metals and alloys, but for accurate radiation influence estimation one needs to measure the same material before irradiation. It is interesting to investigate the "load factor" for high-irradiated steels because of the high ability of irradiated material to deformation localization on mesoscale level (grain, some grains, formation of defect-free channel).

Data were also taken from unirradiated samples provided by the University of Michigan using the same procedures discussed above. Not all conditions were available, however (notably for B and BS conditions). In these cases, unirradiated hardness data were taken from the previous CIR program. The irradiated and unirradiated data are shown together in Table 6 for $500 \mathrm{~g}$ loads.

The hardness data can be used to estimate the change in yield strength using a relation developed by Busby et al. [3]. While there are several possible routes to estimate yield strength from hardness, the most straightforward is given as:

$$
\Delta \sigma_{y}=3.03 \Delta H_{V}
$$

where $\Delta \sigma_{\mathrm{y}}$ is expressed in MPa and $\Delta \mathrm{H}_{\mathrm{v}}$ is expressed in $\mathrm{kg} / \mathrm{mm}^{2}$. 


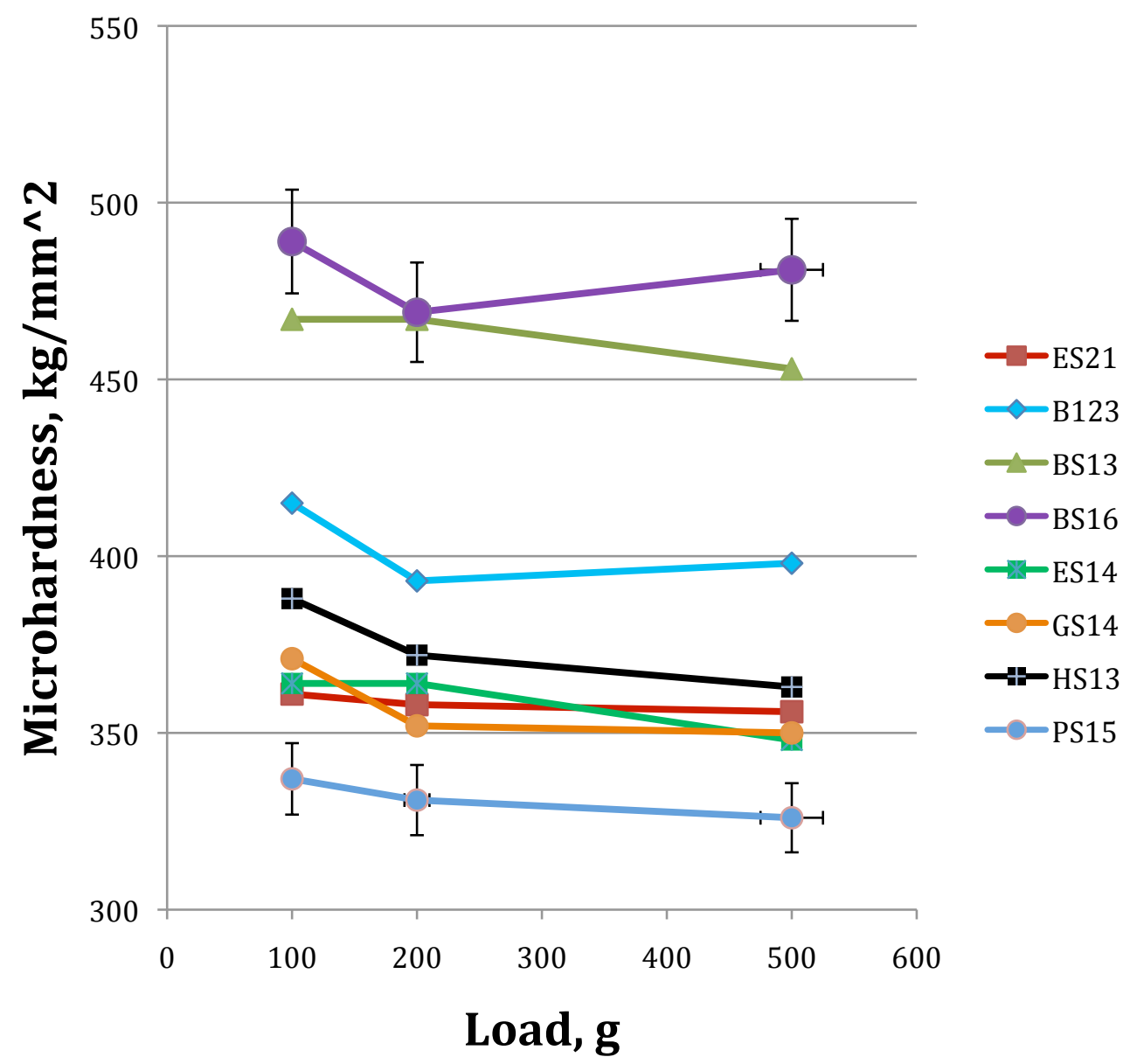

Figure 6: Microhardness value as function of load. For most soft and hard specimens the $3 \%$ error bars are shown.

Table 6: Microhardness values for initial batch of tensile specimens (500 g load).

\begin{tabular}{|c|c|c|c|c|c|c|}
\hline Sample code & Material & Dose, dpa & $\begin{array}{l}\text { Irradiated } \\
\text { Hardness } \\
(\mathrm{kg} / \mathrm{mm} 2) \\
\end{array}$ & $\begin{array}{r}\text { Unirradiated } \\
\text { Hardness } \\
(\mathrm{kg} / \mathrm{mm} 2) \\
\end{array}$ & $\begin{array}{c}\text { Change in } \\
\text { Hardness } \\
(\mathrm{kg} / \mathrm{mm} 2)\end{array}$ & $\begin{array}{l}\text { Change in } \\
\text { Yield Stress } \\
(\mathrm{MPa})\end{array}$ \\
\hline ES21 & HP304 SS & 10.7 & 361 & 119 & 242 & 733 \\
\hline B123 & CW316 & 25 & 415 & $205^{*}$ & 210 & 636 \\
\hline BS13 & SA316* & 5.5 & 467 & $348 *$ & 119 & 361 \\
\hline BS16 & SA316* & 10.2 & 489 & $348 *$ & 141 & 427 \\
\hline ES14 & HP304L & 11.8 & 364 & 119 & 245 & 742 \\
\hline GS14 & HP304+Mo & 11.8 & 371 & 121 & 250 & 758 \\
\hline HS13 & HP304+Si & 7.8 & 388 & 141 & 247 & 748 \\
\hline PS15 & HP304+Hf & 9.6 & 337 & 125 & 212 & 642 \\
\hline
\end{tabular}

*Data taken from previous CIR study 


\subsection{COMPARISON WITH PAST STUDIES}

The results in Table 6 can readily be compared with data in the literature and values from past studies on these same materials. The calculated yield strength from the hardness data of this study are plotted versus measured yield strength from a variety of studies on 316 stainless steel in light water reactors. The data from this study (assuming an unirradiated yield stress of $220 \mathrm{MPa}$ ) are well in line with the expected trends and data from past studies. Further the observed saturation of hardness as a function of dose in this study is consistent with past observations.

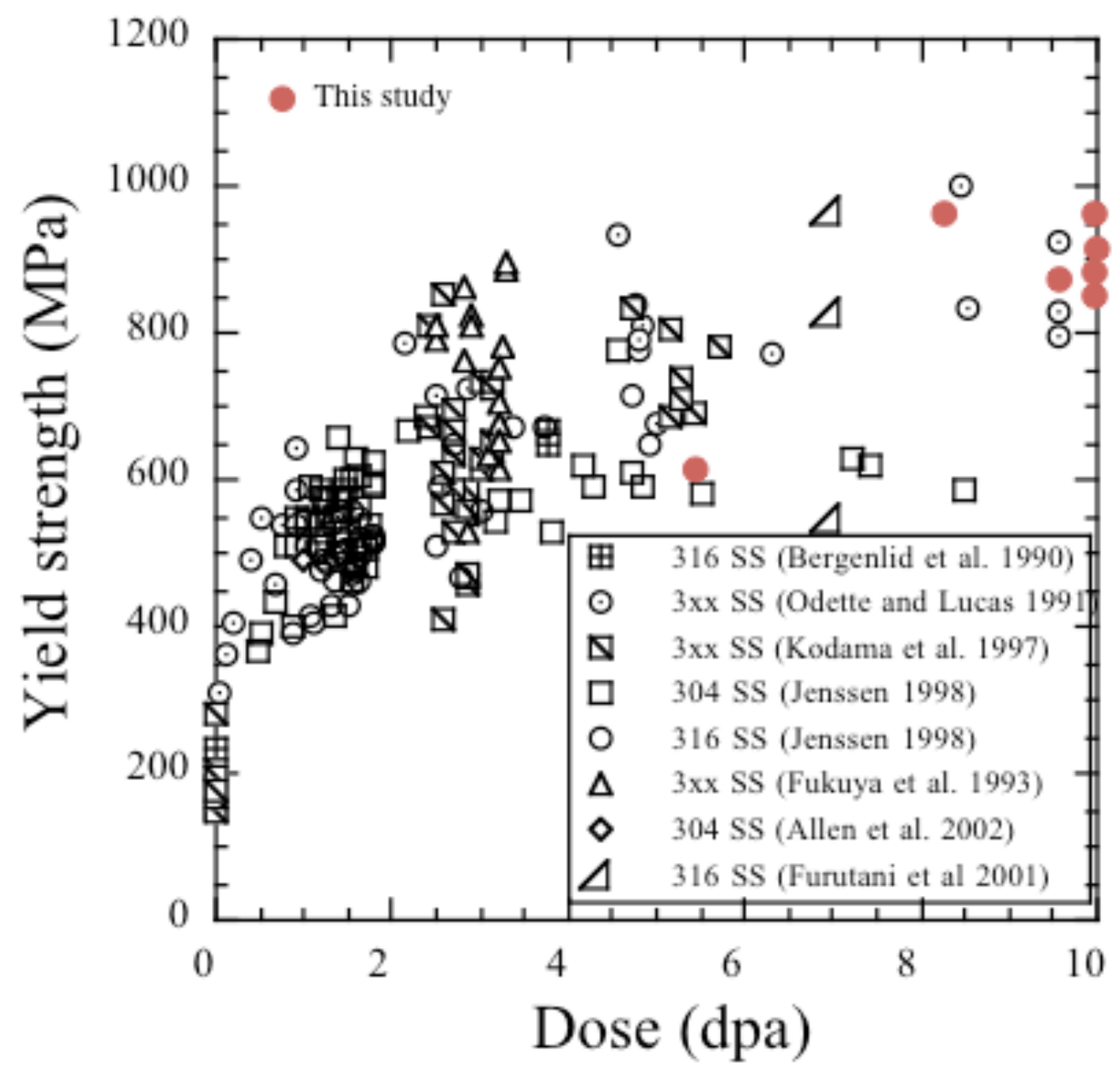

Figure 7: Comparison of irradiation hardening of this work with previous studies on 316 stainless steel in light water reactors. 



\section{ANALYSIS OF DEFORMATION AROUND HARDNESS INDENTATIONS}

After microscopic investigation of the indentations' structure it was found the pyramid indentation during microhardness measurement leads to formation of complex form indentation (see Figure 8, a,b). As a rule, the indentation has deformed borders and as a whole the picture often looks disordered. Sometimes it is possible to receive indentations of good square-form without significant deformation (Figure 8c), but most indentations are deformed and their boundaries have complex nonlinear shapes. Due to the large number of indents, it is possible to try to classify this data.

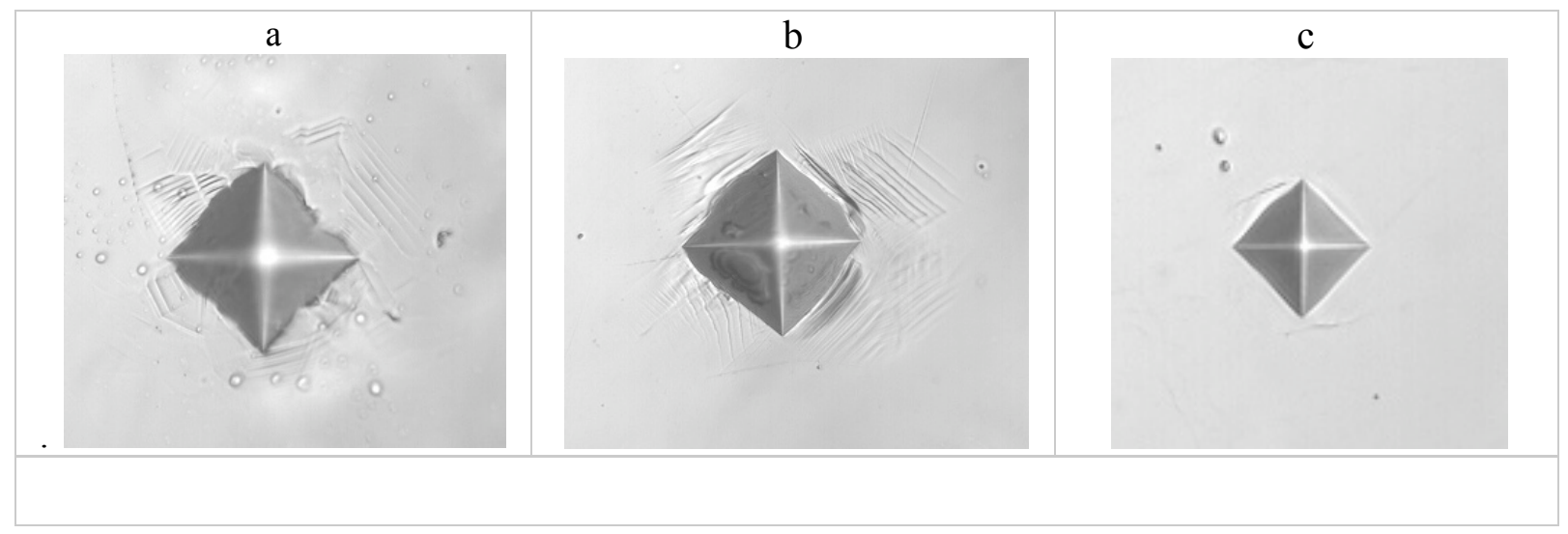

Figure 8: Examples of typical indenter indent geometry: a) HS-13 sample, $500 \mathrm{~g}$ load. b) ES-21, 500 g. c) BS-13, $100 \mathrm{~g}$.

The material of this investigation has regular grain structure and the typical scale of grain size (10-40 microns) is comparable to indent size (20-50 microns). So, each indent's boundary interacts with one or more grains. Because deformation processes are sensitive to grain orientation, it is possible to expect one will see different pictures for each particular grain orientation.

For this analysis, it is easiest to start from indentations with smallest $(100 \mathrm{~g})$ load because the indent border size ( $\sim 20$ microns) is comparable to the grain size. After analysis of $\sim 50$ indents it was found, all indent structures can be divided into 3 main categories:

- Clear straight (or almost straight) border without any deformation signs (or deformation signs are very light) (See Figure 9).

- Border with form-less shaft or heap of deformed material without deformation bands (See Figure 10).

- Clear linear-like structure similar to "hard-wood floor" relief (See Figure 11).

Certainly, given classifications are not fully objective and contain a certain element of arbitrariness. There are images of borders, which can be classified to this or that type, or to allocate in separate "mixed" type. However, for this initial analysis, three categories are sufficient. 


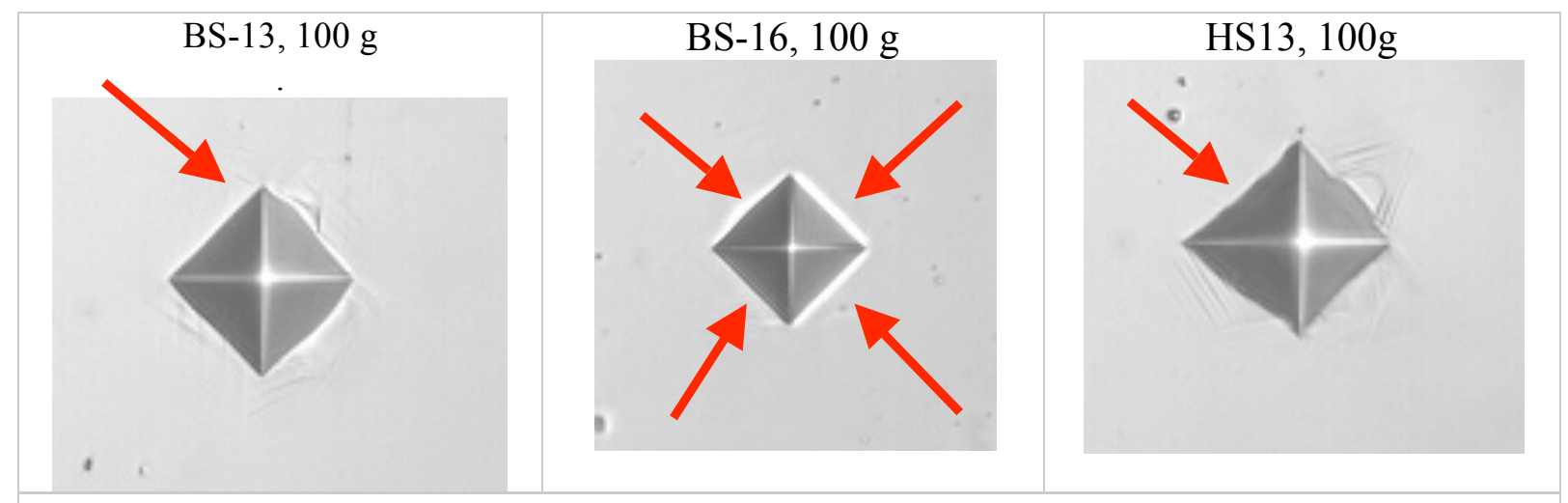

Figure 9: Clear borders of A-type (marked by arrows).

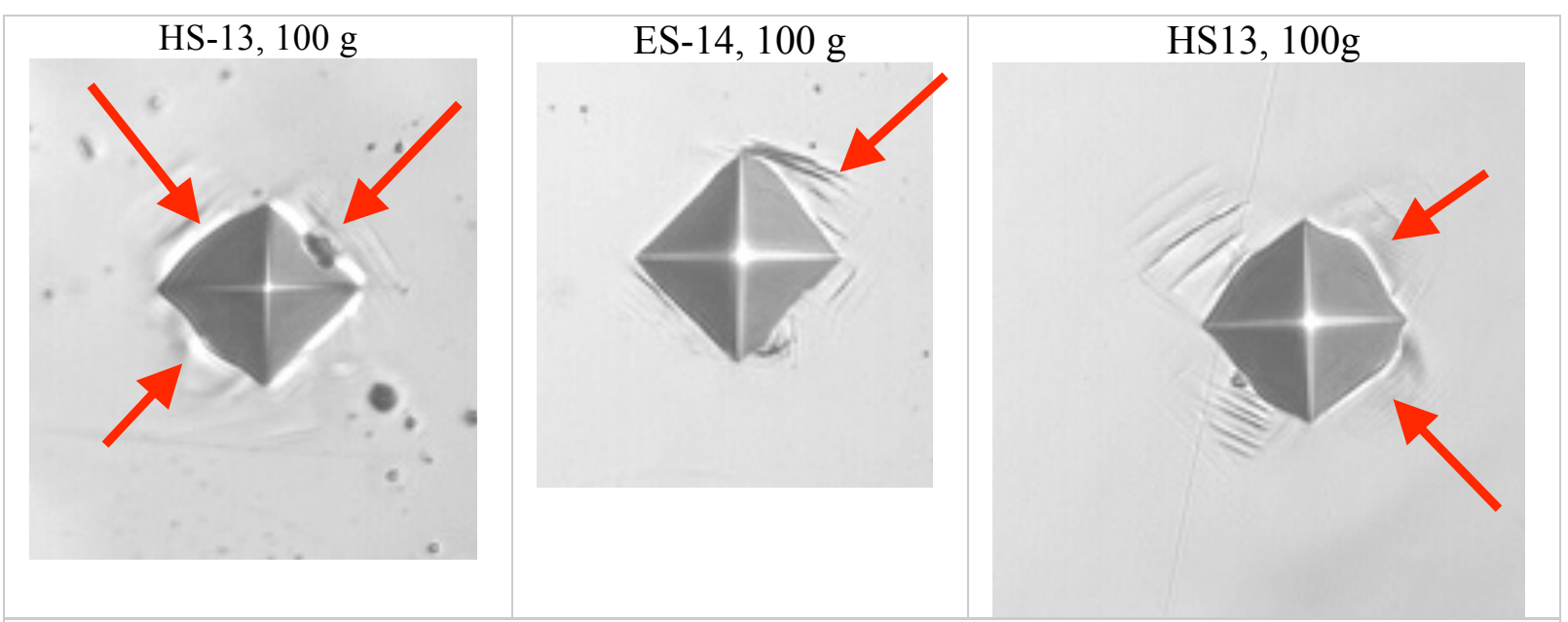

Figure 10: Borders of B-type (marked by arrows). One can see formless "hills" of material.

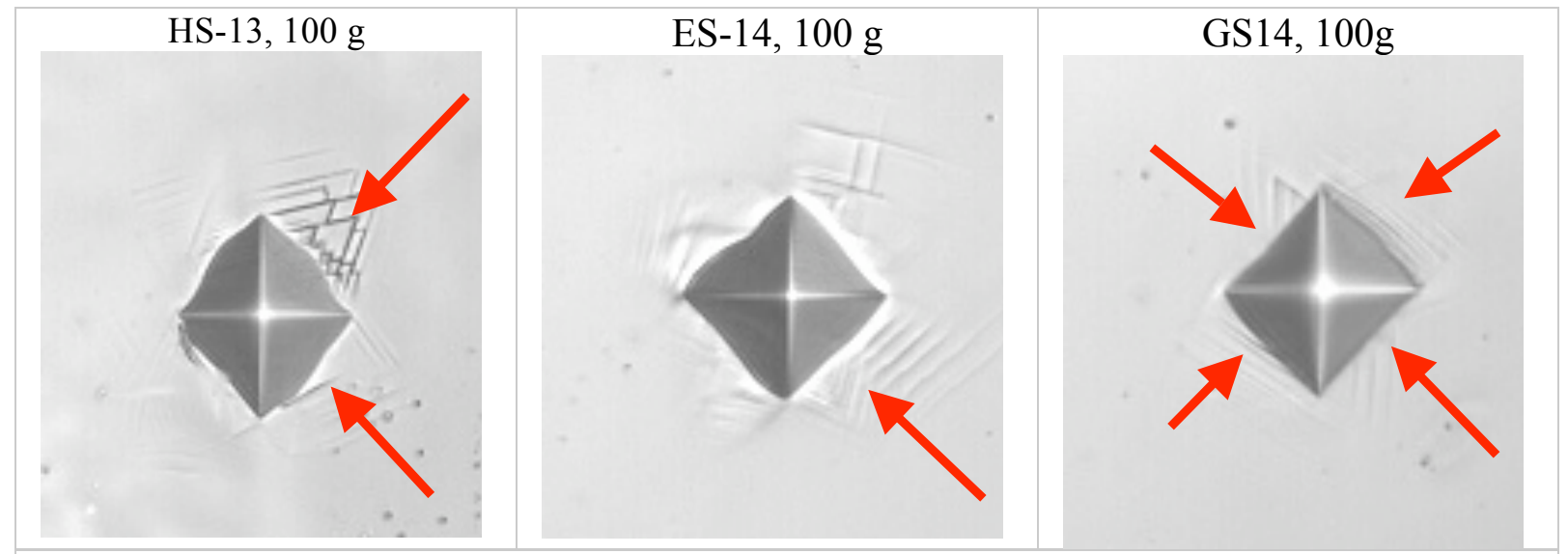

Figure 11: Borders of C-type (marked by arrows). It is possible to see deformation lines as "parquetlike" relief.

As shown on Figures 9-11, the low-load-indent boundary in most cases can be classified as singletype. The loading increase leads to a more complex picture. The border of the indentation now occupies some grains, and high load conducts to formation of complex, break boundary (See Figure 12). 


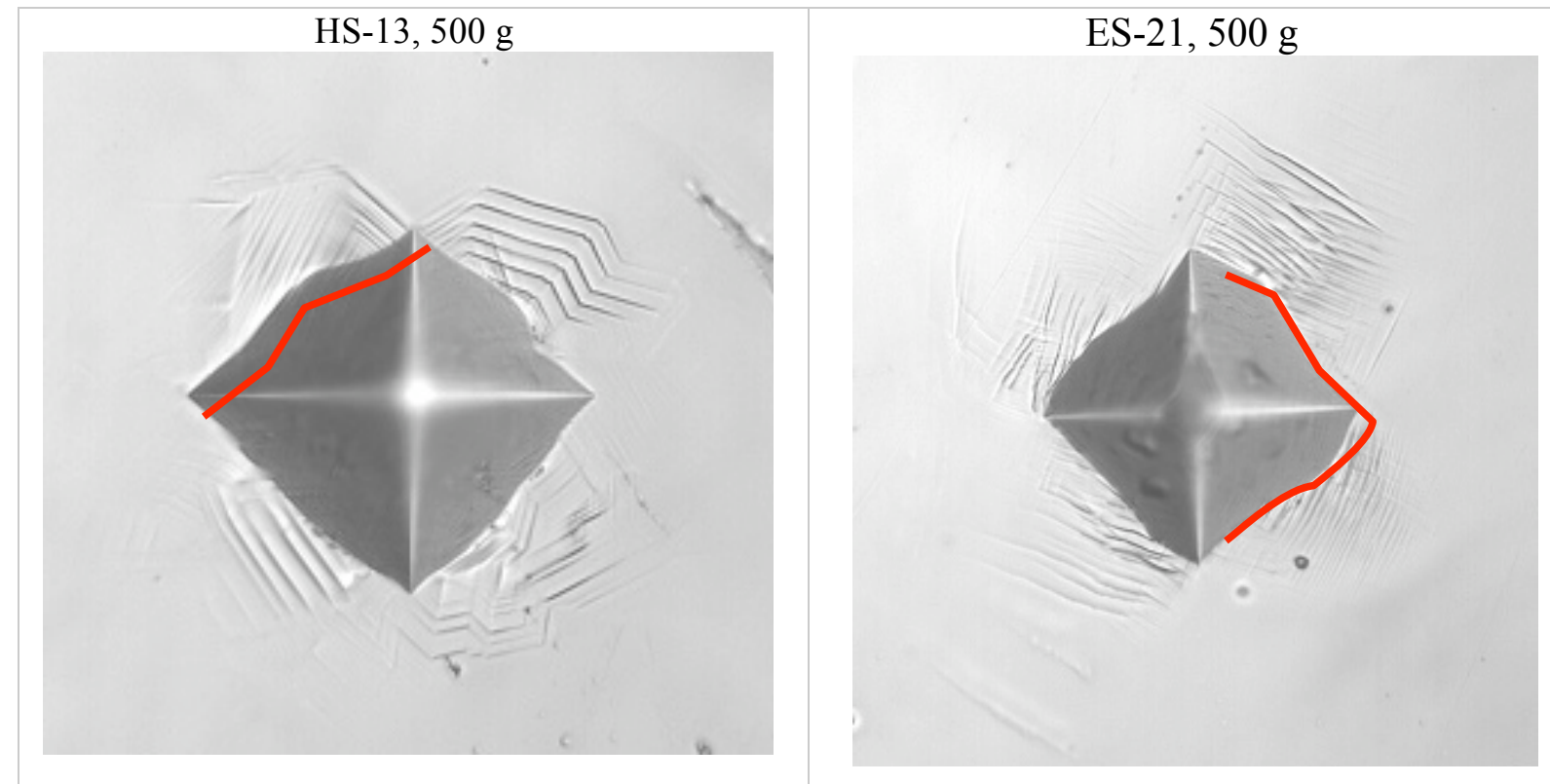

Figure 12: Examples of compels boundary Most of boundaries' perimeter is C-type boundary.

Usually complex shape boundaries for high-load indentations can not be classified as single-type. In most cases it contains parts of different types (see Figure 13).

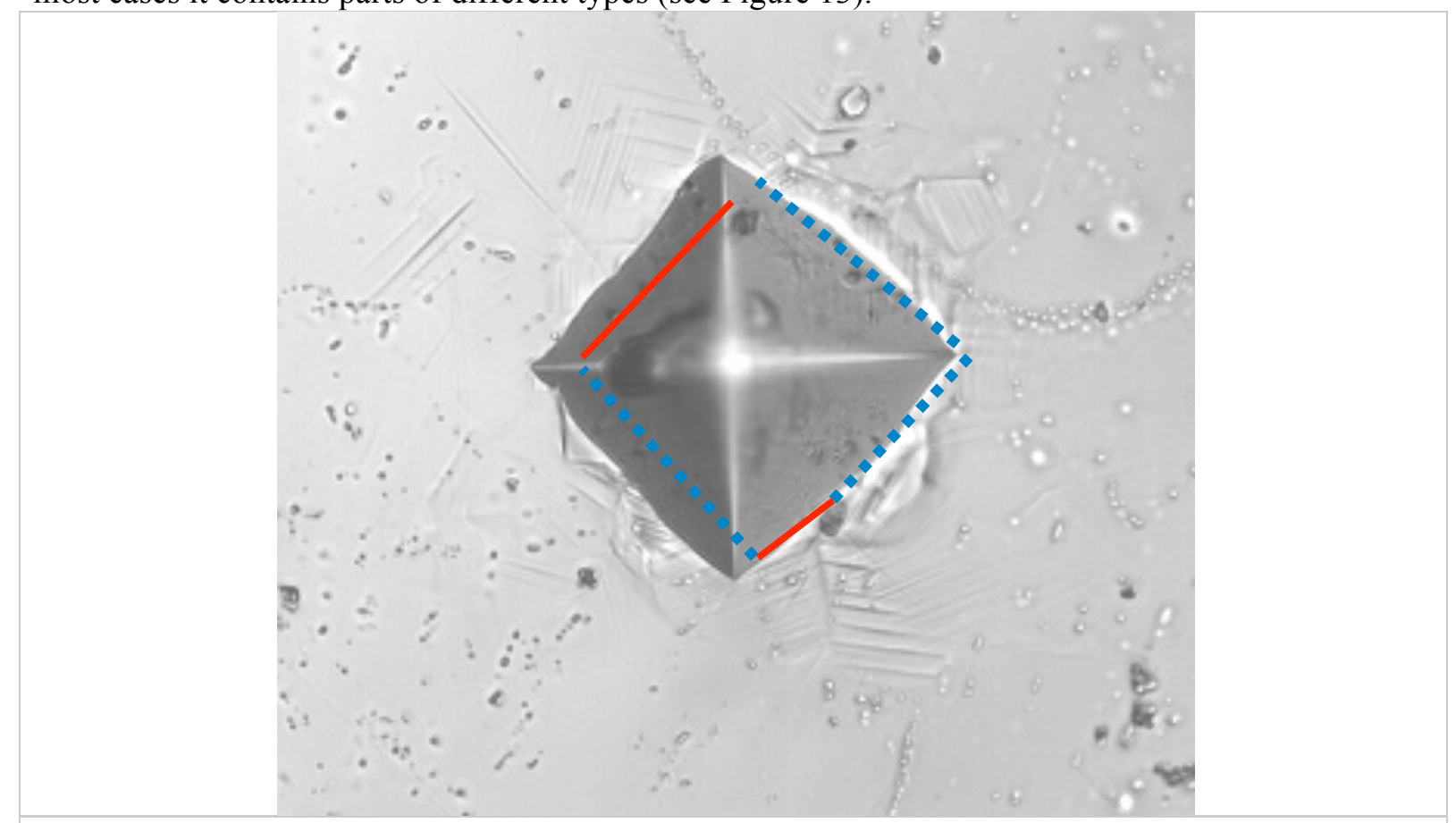

Figure 13: Examples of compels boundary with C (solid line) and B (dot line) parts. PS-15, 500g.

It is possible to assume, the near-boundary structure is connected to the material's deformation mechanisms. So, the structure we see is connected to material composition, structure and history. One can calculate the fractions of the perimeters related to different types and use these data for different estimation (See table 7). 
Table 7: Fraction of different stricture types $(A, B, C)$ for different loads.

\begin{tabular}{|c|c|c|c|c|c|c|c|c|c|}
\hline \multirow{2}{*}{ sample } & \multicolumn{3}{|c|}{ load 100} & \multicolumn{3}{|c|}{ load 200} & \multicolumn{3}{|c|}{ load 500} \\
\hline & $\mathbf{A}$ & B & $\mathrm{C}$ & $\mathbf{A}$ & B & C & $\mathbf{A}$ & B & $\mathrm{C}$ \\
\hline BS16 & 0.66 & 0.33 & $\mathbf{0}$ & 0.45 & 0.5 & 0.05 & 0.3 & 0.45 & 0.25 \\
\hline BS13 & 0.6 & 0.25 & 0.15 & 0.8 & 0.15 & 0.05 & 0.4 & 0.3 & 0.3 \\
\hline PS 15 & 0.55 & 0 & 0.45 & 0.25 & 0.05 & 0.7 & 0.05 & 0.25 & 0.7 \\
\hline ES21 & 0.4 & 0.4 & 0.2 & 0.1 & 0.2 & 0.7 & 0.02 & 0.16 & 0.82 \\
\hline HS13 & 0.4 & 0.25 & 0.35 & 0.15 & 0.05 & 0.8 & 0.1 & 0.15 & 0.75 \\
\hline B123 & 0.35 & 0.2 & 0.4 & 0.05 & 0.05 & 0.9 & 0.05 & 0.2 & 0.75 \\
\hline ES14 & 0.2 & 0.25 & 0.55 & 0.35 & 0.15 & 0.5 & 0.1 & 0.05 & 0.85 \\
\hline GS14 & $\mathbf{0}$ & 0.05 & 0.95 & 0.1 & 0.1 & 0.8 & 0.03 & 0.03 & 0.94 \\
\hline
\end{tabular}

The data in Table 7 is sorted by fraction of A-structure for $100 \mathrm{~g}$ load. That is, A-structure fraction volume (see column A for $100 \mathrm{~g}$ ) decreases from BS16 to GS14 samples. With increasing load, the fraction of A-structure decreases and fraction of C-structure increases (up to $\sim 100 \%$ ). This rule has two major exceptions: BS-samples show a big amount of A-type boundaries for all loads, and the GS14 sample almost always forms C-structure boundaries.

The tendency of dominant structure change can be illustrated by the red diagonal arrow in Table 7: in general the part of C-type structure increases with the increasing of load and from BS-samples to PS15 , ES-21 etc. One should also expect the influence of damage dose, although this question will be studied later in the program when more statistics are available.

However, the exceptions noted above (BS and PS) are very interesting and should be investigated in detail. As a working hypothesis one can accept both of these exceptions (BS-samples and GS14) are connected to unusual sample structures (small or very big grain size) and composition (exotic additions).

The general rule (increasing of $\mathrm{C}$ and decreasing of $\mathrm{A}$ with load increasing) for all others samples may be connected to increasing of material deformed volume with increasing of indentation load. It is possible to assume the $\mathrm{C}$-type structure is connected to the formation of defect-free channels and localized deformation. This phenomenon is well investigated for irradiated metal materials, and it should have some critical volume. Further, the formation of defect-free channel systems can be scalesensitive. If one deforms the small part of grain, the defect free channels can never forms; but if there are many grains under the indenter, the defect-free channel systems can form with high probability. 


\section{DENSITY}

Density and swelling measurements were performed using a procedure based on ASTM standard C135-96 [4]. The density measurements were performed on tensile specimens by an immersion density method. Non-irradiated control specimens were measured with the irradiated specimens for each material condition that was available. The density data from the irradiated specimens is compared with those of the control specimens, and void swelling will be quantified by the radiationinduced density changes. It is important to note that if significant precipitation occurs, the measured density change can be due to void swelling and/or phase change effects.

An immersion density method is widely used in determining the densities of specimens before and after irradiation. Immersion density measurements are based on the Archimedes' principle, and the density of a sample is calculated by its weight difference in air and in liquid. An immersion density measuring apparatus had been developed for previous ORNL programs [5]. The critical factors that affect the precision and accuracy of the measurements have been thoroughly analyzed and refined in the design of the instrument. The performance of the system was evaluated by measuring several high purity metals.

\subsection{IMMERSION DENSITY PRINCIPLE}

Immersion density measurements are based on the Archimedes' principle. The apparent weight reduction of an immersed body is equal to the mass of the displaced liquid. The density of a specimen can be determined by measuring its mass in air and its effective mass when submerged in a liquid with a known-density. The density of the specimen is calculated using the following equation:

$$
\rho_{\text {sample }}=\frac{W_{\text {sample }}^{\text {air }} \times \rho_{\text {fluid }}(T)}{W_{\text {sample }}^{\text {air }}-W_{\text {sample }}^{\text {fluid }}}
$$

where $\rho_{\text {sample }}$ is the density of the specimen, $\rho_{\text {fluid }}(T)$ is the density of the liquid at the test temperature, $\mathrm{T}, \mathrm{W}^{\text {air }}{ }_{\text {sample }}$ is the mass of the specimen in air, and $\mathrm{W}^{\text {fluid }}$ sample is the mass of the specimen in liquid.

The immersion density-measuring unit consists of an ultra-sensitive balance, the Satorius ME215S, a density kit, and a high-precision digital thermometer. The balance has a resolution of $0.010 \mathrm{mg}$ and a reproducibility of $\pm 0.015 \mathrm{mg}$ in a weight range of $0-60 \mathrm{~g}$. The digital thermometer has a resolution of $0.001^{\circ} \mathrm{C}$ with an accuracy of $\pm 0.05^{\circ} \mathrm{C}$. The density kit includes a beaker filled with a high-density fluid, a specimen holder, a thin wire (0.007 in. in diameter) for suspending the specimen holder in liquid, and a metal platform supporting the beaker. The entire density unit is set up on a marble table in a stable environment to minimize vibrations and temperature perturbations.

3M Fluorinert ${ }^{\mathrm{TM}}$ Liquid FC-43 was chosen as the preferred liquid due to its high density (nearly double that of water at room temperature). It also has low surface tension, low thermal expansion, low vapor pressure, and low water/air solubility, which are critical factors in measuring densities accurately. Since the liquid density is primarily affected by temperature variations, the temperature dependence of FC-43 density needs to be determined accurately. The density-temperature relation of FC-43 was derived from the data obtained by measuring National Institute of Standards and Technology (NIST) traceable marble standards of known densities $\left(2.699,2.900\right.$ and $\left.3.200 \mathrm{~g} / \mathrm{cm}^{3}\right)$. The density data were fitted using both a linear function and an exponential function. Figure 14 shows the calibrated density of FC-43 as a function of temperature. The exponential fitting gave a coefficient of 0.0012 , which agrees with the thermal expansion coefficient of this fluid. The linear temperature dependence was employed for simplicity, and is given as: 


$$
\rho\left(\mathrm{g} / \mathrm{cm}^{3}\right)=1.93511-0.00223 \times T\left({ }^{\circ} \mathrm{C}\right)
$$

All the density measurements are carried out at room temperature.

The general procedure for measuring the densities of refractory alloy specimens begins with zeroing the balance and weighing the specimen in air. A beaker is then filled with approximately $300 \mathrm{ml}$ of the FC-43 solution. The beaker is placed on a metal platform that rests on the base of the weighing chamber and a specimen holder is suspended in the solution using a thin wire. After allowing the solution to stabilize for at least an hour, the specimen is placed in the solution and allowed to completely wet. The balance is then zeroed and the weight of the immersed specimen is recorded. The liquid density at the measuring temperature is determined by eq. (2).

The specimen densities are calculated using eq. (4) that accounts for air buoyancy ( $\rho$ air $=0.0012$ $\mathrm{g} / \mathrm{cm} 3$ at $\mathrm{T}=20^{\circ} \mathrm{C}$ and $\mathrm{P}=101.325 \mathrm{kPa}$ ), i.e.

$$
\rho_{\text {sample }}=\frac{W_{\text {sample }}^{\text {air }} \times\left(\rho_{\text {fluid }}(T)-\rho_{\text {air }}\right)}{\left(W_{\text {sample }}^{\text {air }}-W_{\text {sample }}^{\text {fluid }}\right)}+\rho_{\text {air }}
$$

A standard specimen is measured to calibrate the density measuring unit before measuring test specimens. Each specimen is measured three times. If more than three measurements are made, the highest and lowest values are discarded and the average and standard derivation were calculated from the remaining three measurements.

Several high purity metals, $\mathrm{Fe}, \mathrm{Cu}, \mathrm{Mo}, \mathrm{Ag}$, and $\mathrm{Pd}$, have been measured in past campaigns to evaluate the performance of the immersion density measuring unit. The materials selected span a range of density between 8 and $21 \mathrm{~g} / \mathrm{cm}^{3}$. The results [5] indicate that the density measurements are both repeatable and accurate over a wide range of densities. The measured density for copper is lower than the published value from [6] for both sets of data. 


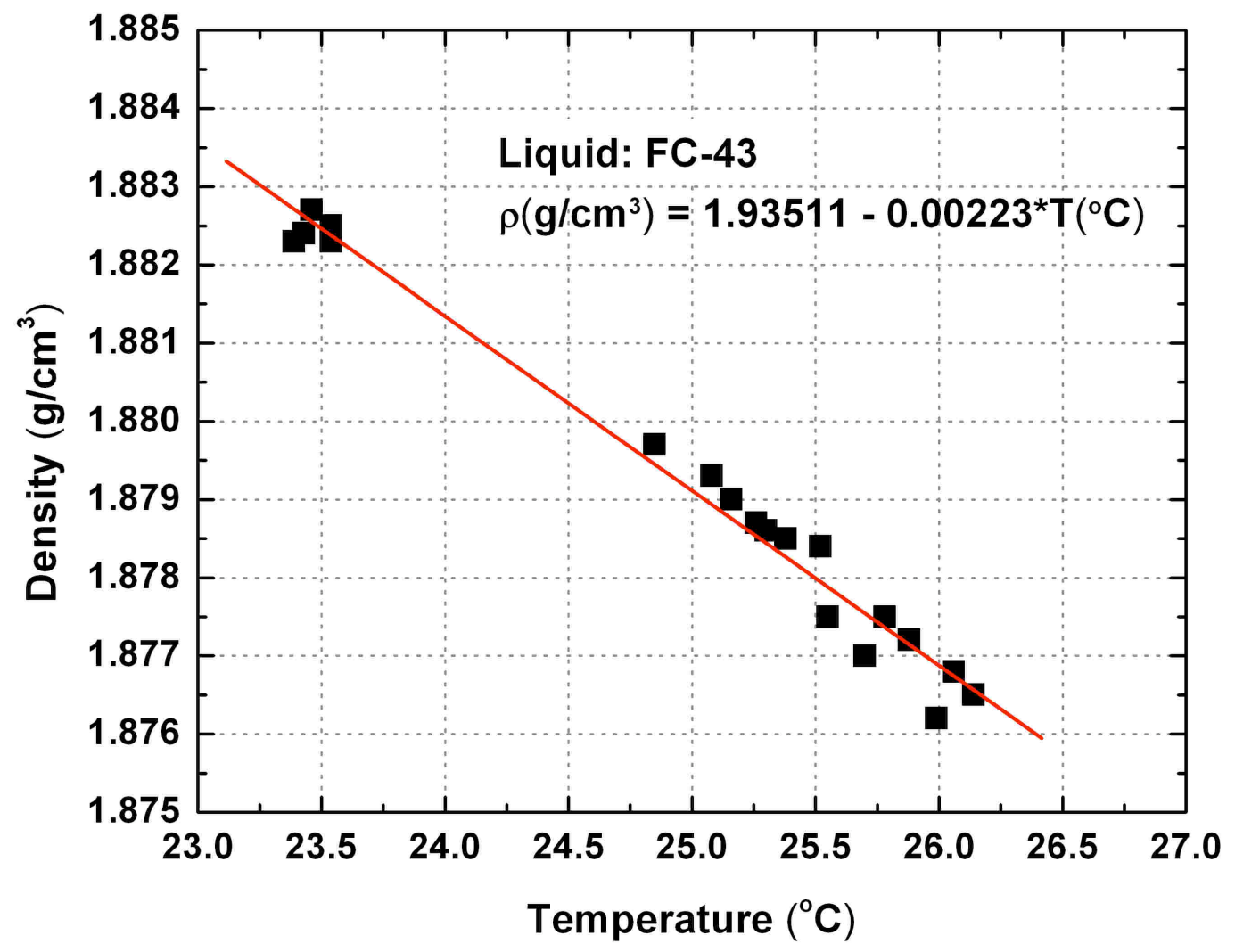

Figure 14: Temperature dependence of FC-43 density.

\subsection{IMMERSION DENSITY RESULTS}

For density measurements of this study, the procedure described above was used. Each sample was weighted 3 times in air and 3 times in liquid. The temperature was measured with accuracy not worse than $0.2^{\circ} \mathrm{C}$ before and after each sample measurement. The sample code, material, damage dose, and density values are given in Table 8 for all samples. Data on the samples' weight in water and in air are listed for reference. 
Table 8: Density values for first set of BOR-60 samples

\begin{tabular}{|c|c|c|c|c|c|c|}
\hline $\begin{array}{c}\text { Sample } \\
\text { code }\end{array}$ & Material & $\begin{array}{c}\text { Dose, } \\
\text { dpa }\end{array}$ & $\begin{array}{c}\text { Average } \\
\text { weight in } \\
\text { air }\end{array}$ & $\begin{array}{c}\text { Average } \\
\text { weight in } \\
\text { water }\end{array}$ & $\begin{array}{c}\text { Density, } \\
\text { g/cm }\end{array}$ & $\begin{array}{c}\text { Swelling } \\
(\%)\end{array}$ \\
\hline B123 & CW316 & 25 & 2.25007 & 1.717163 & 7.954 & $0.58 \%$ \\
\hline BS13 & SA316 & 5.5 & 1.838767 & 1.402463 & 7.938 & $0.78 \%$ \\
\hline BS16 & SA316 & 10.2 & 1.828937 & 1.39475 & 7.934 & $0.82 \%$ \\
\hline ES21 & HP304 & 10.7 & 1.819207 & 1.388913 & 7.964 & $0.45 \%$ \\
\hline ES14 & HP304L & 11.8 & 1.83001 & 1.39734 & 7.967 & $0.41 \%$ \\
\hline HS13 & HP304+Si & 7.8 & 2.12617 & 1.618463 & 7.888 & $1.40 \%$ \\
\hline PS15 & HP304+Hf & 9.6 & 2.149903 & 1.64641 & 8.043 & $-0.54 \%$ \\
\hline GS14 & HP304+Mo & 11.8 & 1.857243 & 1.420707 & 8.013 & $-0.16 \%$ \\
\hline
\end{tabular}

It is possible to see from the table, density values for B123, BS13, and BS16 are relatively close to each other. Since the damage doses for all HP-samples (high purity 304 steel) are similar, one can compare density values and try to assess the role of alloying elements. There is no difference in the ES series of alloys. Addition of Si to HP304 steel (sample HS13) decreases the density after irradiation, but addition of Hf or Mo (samples PS15 and GS14 respectively) leads to increasing of density, although the difference for the GS alloy is likely within the uncertainty of the measurement. Densification is observed for the PS alloy. This may be due to the formation of Hf-rich phases under irradiation and more analysis is required. 


\section{SUMMARY}

The Light Water Reactor Sustainability (LWRS) Program is designed to support the long-term operation (LTO) of existing domestic nuclear power generation with targeted collaborative research programs into areas beyond current short-term optimization opportunities. The Materials Aging and Degradation Pathway is designed to help develop the scientific basis for understanding and predicting long-term environmental degradation behavior of materials in nuclear power plants and to provide data and methods to assess performance of systems, structures, and components essential to safe and sustained operation.

Extended service conditions will increase the exposure to irradiation, stress, and corrosive environment for all core internal components. The effects of irradiation can substantially increase susceptibility to stress-corrosion cracking of austenitic steels in high-temperature water environments. IASCC is a key materials degradation issue in today's nuclear power reactor fleet and affects critical structural components within the reactor core. Despite 30 years of experience, the underlying mechanisms of IASCC are unknown. The objective of this work is to evaluate the response and mechanisms of IASCC in austenitic stainless steels with single variable experiments.

A series of high-value irradiated specimens has been acquired from the past CIR program, providing a valuable opportunity to examine the mechanisms of IASCC. This batch of irradiated specimens has been received and inventoried. In addition, visual examination and sample cleaning has been completed.

Microhardness testing has been performed on these specimens. All samples show evidence of hardening, as expected, although the degree of hardening has saturated and no trend with dose is observed. Further, the change in hardening can be converted to changes in mechanical properties. The calculated yield stress is consistent with previous data from light water reactor conditions.

In addition, some evidence of changes in deformation mode was identified via examination of the microhardness indents. This analysis may provide further insights into the deformation mode under larger scale tests.

Finally, swelling analysis was performed using immersion density methods. Most alloys showed some evidence of swelling, consistent with the expected trends for this class of alloy. The Hf-doped alloy showed densification rather than swelling. This observation may be related to the formation of second-phases under irradiation, although further examination is required. 



\section{REFERENCES}

1. Light Water Reactor Sustainability Research Program Plan, INL Document, INL/MIS-0814918 rev 3, September 2010.

2. G.S. Was, Y. Ashida, K. Stephenson, and P. Andresen, "Identifying Mechanisms and Mitigation Strategies for Irradiation Assisted Stress Corrosion Cracking of Austenitic Steels in LWR Core Components," University of Michigan Semi-annual report, Sept. 2010.

3. J.T. Busby, M.C. Hash, and G.S. Was, "The Relationship Between Hardness and Yield Stress in Irradiated Austenitic and Ferritic Steels," J. Nucl. Mater. Vol. 336, 2-3 (2005), 267-278.

4. "Standard Test Method for True Specific Gravity of Refractory Materials by Water Immersion", ASTM Designation C135-96. ASTM Standards Online, American Society for Testing and Materials, Philadelphia, PA, 2003.

5. Meimei Li, "Final Report on Post Irradiation Density Measurements of Molybdenum Specimens from Phases I, II \& III," ORNL report to Naval Reactors, 2004 via private communication.

6. CRC Handbook of Chemistry and Physics, 84th Ed. CRC Press, Boca Raton, FL, 2003-2004. 
This page intentionally left blank 


\section{INTERNAL DISTRIBUTION}

1. J. T. Busby

3. M. Gussev

5. S. Zinkle
2. T. Rosseel

4. D. Williams

\section{EXTERNAL DISTRIBUTION}

6. R. Szilard, Idaho National Laboratory, P.O. Box 1625, Idaho Falls, ID 83415-3860, (Ronaldo.Szilard@inl.gov)

7. P. Finck, Idaho National Laboratory, P.O. Box 1625, Idaho Falls, ID 83415-3860, (Phillip.Finck@inl.gov)

8. R. Reister, GTN Bldg, 1000 Independence Ave, S.W. Washington, DC 20585, (Richard.Reister@nuclear.energy.gov) 
